\title{
APPLICATIONS AND CRITICAL EVALUATION OF FASCIA ILIACA COMPARTMENT BLOCK AND QUADRATUS LUMBORUM BLOCK FOR ORTHOPEDIC PROCEDURES
}

\author{
Mihovil Plečko, Ivan Bohaček, Branko Tripković, Mislav Čimić, Mislav Jelić, Domagoj Delimar \\ Department of Orthopaedic Surgery, University Hospital Centre Zagreb, \\ School of Medicine, University of Zagreb, Zagreb, Croatia
}

\begin{abstract}
SUMMARY - Anterior section of the hip joint capsule is innervated by femoral nerve and obturator nerve, and posterior section is innervated by the nerve to quadratus femoris muscle and occasionally by the superior gluteal (posterolateral region) and sciatic nerve (posterosuperior region). One of the regional anesthesia options for hip surgery is the fascia iliaca compartment block (FICB) that affects nerves important for hip innervation and sensory innervation of the thigh - femoral, obturator and lateral femoral cutaneous nerve. FICB can be easily performed and is often a good solution for management of hip fractures in emergency departments. Its use reduces morphine pre-operative requirement for patients with femoral neck fractures and can also be indicated for hip arthroplasty, hip arthroscopy and burn management of the region. Quadratus lumborum block (QLB) is a block of the posterior abdominal wall performed exclusively under ultrasound guidance, with still unclarified mechanism of action. When considering hip surgery and postoperative management, the anterior QLB has shown to reduce lengthy hospital stay and opioid use, it improves perioperative analgesia in patients undergoing hip and proximal femoral surgery compared to standard intravenous analgesia regimen, provides early and rapid pain relief and allows early ambulation, thus preventing deep vein thrombosis and thromboembolic complications etc. However, some nerve branches responsible for innervation of the hip joint are not affected by QLB, which has to be taken into consideration. QLB has shown potential for use in hip surgery and perioperative pain management, but still needs to be validated as a reliable treatment approach.
\end{abstract}

Keywords: hip joint innervation; regional anesthesia; orthopedic surgery; fascia iliaca compartment block; quadratus lumborum block

\section{Sensory innervation of the hip joint}

The hip joint is a classical ball-and-socket joint formed by an articulation between head of the femur and the acetabulum surrounded by a cartilaginous labrum. The whole joint is covered by a joint capsule and additionally stabilized by ischiofemoral, iliofemoral and pubofemoral ligament, together with many mus-

Corresponding author: Ivan Bohaček, $M D, P h D$, Department of Orthopaedic Surgery, University Hospital Centre Zagreb, Šalata 6, 10000 Zagreb, Croatia

e-mail: ivan.bohacek@gmail.com cles that either originate in, insert or just pass by this area (1). Innervation of the hip joint is derived from both lumbar (L1-L4) and sacral (L4-S4) plexuses (2). An anatomical study showed that the anterior section of the hip joint capsule is innervated by the articular branches of the femoral nerve and the obturator nerve. Femoral nerve originates from L2-L4 nerve roots, passing through illiopsoas and running deep to inguinal ligament. It gives articular branches that innervate the anterolateral part of the hip joint capsule, and gives branches for sensation in anteromedial thigh as well, the medial and intermediate femoral cutaneous nerves 
of the thigh. In some cases, an accessory femoral nerve is found, innervating the anterior section of the capsule. The obturator nerve originates from L2-L4 nerve roots, descending medially through psoas muscle, passing behind common iliac vessels, continuing along lateral wall of the lesser pelvis and entering the thigh through the obturator canal. It gives articular branches for the anteromedial section of the hip joint capsule and for the medial aspect of the thigh and knee joint. The posterior section of the hip joint capsule is most commonly supplied by two articular branches from the nerve to quadratus femoris muscle that originates from the L4-S1 nerve roots. One of these branches passes to the posteroinferior and the other one to the posterolateral part of the joint capsule. Nerve to quadratus femoris muscle can occasionally originate from the sciatic nerve. In some cases, articular branches for the posterior section can originate from the superior gluteal nerve (for the posterolateral region) and from the sciatic nerve directly (for the posterosuperior region) (3).

\section{Applications of fascia iliaca compartment block}

When considering regional anesthesia for hip surgery and pain management, there are several different approaches, such as lumbar plexus block/psoas sheath block, lumbar plexus block/psoas compartment block, lumbar paravertebral block, femoral nerve block, superior gluteal nerve block/sciatic nerve block, spinal and epidural anesthesia etc.(2). One of these approaches is the fascia iliaca compartment block (FICB). Fascia iliaca covers psoas major and iliacus muscles. It originates from lower thoracic vertebrae, distally attaching to the anteriorly positioned fascia lata and reaching all the way to the anterior thigh. The fascia iliaca compartment is a virtual space anteriorly limited by the posterior surface of the fascia iliaca, posteriorly by the iliacus muscle and is cranially in continuation with the space between quadratus lumborum muscle and its fascia (1). Three important nerves for hip innervation and sensory innervation of the thigh are located in this space, the femoral nerve, obturator nerve and lateral femoral cutaneous nerve. Lateral femoral cutaneous nerve is a purely sensory nerve originating from the lumbar plexus (L2 - L3), emerging from the lateral side of the psoas major muscle and crossing the iliacus muscle obliquely, continuing towards anterior superior iliac spine and passing under the inguinal ligament through the lacuna musculorum. It then divides into anterior branch responsible for sensory innervation of the anterior and lateral thigh as far as the knee, and posterior branch that passes backwards and innervates the skin superior to the greater trochanter down to the middle of the thigh (1). Moreover, the obturator nerve runs through the psoas muscle, and can be variably blocked by this type of approach (4). Landmarks for orientation when performing FICB are the anterior superior iliac spine and the pubic tubercle (inguinal ligament). When performing the infra-inguinal approach, this area is divided into thirds, and the injection site is located $1-2$ centimeters below the inguinal ligament between the lateral and middle third (2). It can be performed without ultrasound guidance. When performing without ultrasound guidance, a characteristic " 2 pops" are felt that indicate entrance into the compartment (4). A study reported an increased frequency of sensory loss in the medial aspect of the thigh when using ultrasound guided FICB. Also, ultrasound guidance increased the frequency of femoral and obturator motor block (5). Literature also describes a supra-inguinal ultrasound guided approach (6). A suprainguinal FICB produces a more complete sensory block of the medial, anterior and lateral region of the thigh when compared to infra-inguinal FICB. Additionally, supra-inguinal FICB leads to a more consistent spread in the cranial direction, thus spreading the anesthetic more consistently towards the lumbar plexus and three targeted nerves. Authors suggest that a sufficient volume to reach femoral nerve, obturator nerve and lateral femoral cutaneous nerve using FICB should be $40 \mathrm{~mL}(7,8)$. However, the supra-inguinal approach has a superior postoperative analgesic efficacy compared to infra-inguinal approach along with significantly less morphine consumption in the first 24 hours following total hip arthroplasty (8). Absolute contraindications for this technique are patient's unwillingness to consent to the procedure, known allergy to local anesthetics, local anesthetic injection which has already approached the maximum dosage, previous femoral bypass surgery or close positioning of a graft, local infection at the injection site and relative contraindications are use of anticoagulant therapy with INR $>1.5$, with need for consideration of recent clopidogrel/high dose aspirin/low molecular weight heparin 
consumption $(4,9)$. FICB can be easily performed, and is often a good solution for management of hip fractures in emergency departments (10). Also, studies report on paramedics using FICB on patients with suspected hip fracture at the scene of injury (11). A systematic review on efficacy of prehospital analgesia with FICB for femoral fractures concluded that FICB is suitable for use in the prehospital environment for pain management, with few adverse effects and can be performed with a high success rate by practitioners of any background (12). FICB proved to provide superior analgesia compared to intravenous use of fentanyl before positioning patients for spinal anesthesia when undergoing surgery for femoral neck fractures of all types $(13,14)$. Also, FICB reduced morphine requirement pre-operatively for patients with femoral neck fractures, it can be indicated for hip arthroplasty, hip arthroscopy and burn management of the region innervated by nerves blocked by FICB as well (15-18). A study reports on reduced morphine consumption after total hip arthroplasty when a longitudinal highdose supra-inguinal fascia iliaca compartment block was used (19). Furthermore, continuous femoral block was compared with FICB in patients undergoing hip arthroplasty, and it was concluded that both techniques have equivalent postoperative analgesic efficacy without any difference in functional outcome. Additionally, it was concluded that the fascia iliaca compartment catheter can be placed more quickly than the femoral nerve catheter, but the onset time of sensory and motor blockade is longer when performing the FICB (16).

\section{Critical evaluation of quadratus lumborum block}

The quadratus lumborum (QL) muscle is located in the posterior abdominal wall, placed dorsal and lateral to the psoas major muscle. It originates from the posterior part of the iliac crest and iliolumbar ligament and inserts on the $12^{\text {th }}$ rib and transverse processes of L1 - L5 vertebrae (1). QL is covered by the thoracolumbar fascia (TLF). TLF is a complex structure that separates paraspinal muscles from the muscles of the posterior abdominal wall, QL and psoas major (20). It is formed from three layers; posterior layer is posterior to the erector spinae muscle, the middle layer is placed between the erector spinae and QL muscle and the anterior layer is anterior to $\mathrm{QL}$ muscle. The anterior layer blends medially with the fascia of the psoas major and blends laterally with the transversalis fascia (21). Quadratus lumborum block (QLB), referred to as the "interfascial plane block", was first described in 2007 as a block of the posterior abdominal wall performed exclusively under ultrasound guidance. It was defined as a variant of a transversus abdominis plane block. It was developed in search for a wider analgesia coverage and long-lasting postoperative analgesia (22). The QL muscle is marked as the crucial ultrasound landmark to perform a block and it is considered that TLF plays an important role in QLB analgesia. However, the true mechanism of analgesia of the QLB is not yet clarified. Local spread of anesthetics along the TLF is assumed to be responsible for part of the analgesia. An additional mechanism of action is explained by the characteristics of the TFL, which embeds a thick network of sympathetic neurons. Also, there are high-threshold and low-threshold mechanoreceptors and pain receptors sensitive to the effects of the local anesthetics that could, at least partially, explain the effects of the analgesia of QLB (22). Literature describes four different types of QLB depending on the needle tip positioning in relation to $\mathrm{QL}$ muscle - anterior, posterior, lateral and intramuscular QLB. In anterior QLB local anesthetic is applied in front of the QL muscle, at the level of its attachment to the processus transversus of the L4 vertebra. In posterior QLB local anesthetic is applied behind the QL muscle and in front of the medial lamina of TLF which separates QL muscle from the latissimus dorsi muscle and erector spinae muscle. In lateral QLB local anesthetic is applied on the lateral side of the QL muscle in the area of its contact with transversalis fascia, at the level where transversus abdominis muscle narrows into its aponeurosis. In intramuscular QLB local anesthetic is applied directly into QL muscle. Different needle tip positioning showed to play a crucial role on anesthetic spreading when performing QLB (23). In general, QLB proved to be effective in postoperative analgesia following both cesarean section and gynecologic laparoscopic surgery, as well as for postoperative analgesia after different abdominal surgery procedures (i.e. colon resection, appendectomy, hernioplasty etc.) (24-26). When considering hip surgery and postoperative management, the anterior QLB may play a role in analgesia. It can be performed in a manner that the patient is placed 
into a lateral position with the needle inserted through the $\mathrm{QL}$ in an anteromedial direction. The local anesthetic is injected between the QL muscle and psoas major muscle under ultrasound guidance (23). Authors describe the Shamrock sign that helps with the ultrasound orientation when performing anterior QLB. The three leaves of the shamrock are formed from QL muscle, psoas major muscle and erector spinae muscle, while the transverse process of L4 constitutes the stem (27). A study on cadavers using dye injections showed that anterior QLB may potentially provide analgesia from T10 to L3 nerve roots (28). Moreover, subcostal QLB (a subtype of anterior QLB) has shown to produce anesthesia from the dermatomes of T6-7 to L1-2 (29). QLB employment in hip surgery has shown to reduce length of stay in hospital and intraoperative fentanyl use (30). Few cases have shown QLB to be beneficial in management of proximal femoral fractures in high-risk geriatric patients and a patient that underwent hemiarthroplasty after a femoral neck fracture $(31,32)$. A double-blinded, prospective, randomized, feasibility study showed that QLB improves analgesia quality in patients undergoing hip and proximal femoral surgery when compared to standard intravenous analgesia regimen (33). Moreover, a study showed that QLB block provides improved immediate postoperative analgesia and decreased opioid use compared to multimodal pain regimen following hip arthroscopy (34). Few studies also suggest that QLB might provide similar analgesia in comparison with lumbar plexus block for total hip arthroplasty $(35,36)$. Johnston \& Sondekoppam reported on a case of effective use of continuous QLB analgesia for the perioperative pain management of an opioid-dependent patient undergoing revision hip arthroplasty surgery (37). Akerman et al. highlighted that QLB provides early and rapid pain relief in a high percentage of patients and allows early ambulation, which is one of the most important measures in the prevention of deep vein thrombosis and thromboembolic complications (22). Two cases suggested that QLB may provide effective postoperative analgesia for congenital hip dislocation surgery (38). However, Ince et al. stated that the innervation of the bones has its own pattern and that does not directly correlate to the innervation of more superficial structures such as muscle and skin and raised a question how does QLB provide postoperative analgesia in hip surgery cases with pelvic oste- otomies as Ashikliogul et al. report on. They also highlight that some nerve branches responsible for innervation of the hip joint arise from levels which are not affected by QLB (39). Another issue that arises is the volume of local anesthetic used for achieving proper analgesia. Variable volumes of local anesthetic were used in studies when performing QLB. Ueshima et al. report that there is still no consensus on the volume needed for proper QLB analgesia (23). Complications following QLB are luckily rare. Nevertheless, a case of motor weakness following QLB was reported, which may postpone early mobilization of patients who underwent hip surgery that plays a crucial role in recovery (40). Other complications that may arise are infection at the site of injection, development of local anesthetic systemic toxicity, development of hematoma etc. (22). Bugada et al. state there may be a role for QLB in multimodal pain management for hip surgery patients due to its potential for analgesic effectiveness and preservation of muscle strength, which makes it less likely to impair early functional rehabilitation (41). To summarize, QLB has shown potential for use in hip surgery perioperative pain management, but still lacks sufficient data from prospective studies to be accepted as a reliable treatment approach.

\section{References}

1. Standring S. Gray's Anatomy International Edition: The Anatomical Basis of Clinical Practice. Elsevier Health Sciences; 2015.

2. Halaszynski T, Uskova A. Regional Anesthesia for Hip Surgery. In 2016. p. 1-7.

3. Birnbaum K, Prescher A, Hessler S, Heller KD. The sensory innervation of the hip joint--an anatomical study. SurgRadiol Anat. 1997;19(6):371-5.

4. Pepe J, Madhani NB. Ultrasound-guided Fascia Iliaca Compartment Block. In Treasure Island (FL); 2018.

5. Dolan J, Williams A, Murney E, Smith M, Kenny GNC. U1trasound guided fascia iliaca block: a comparison with the loss of resistance technique. Reg Anesth Pain Med. 2008;33(6): 526-31.

6. Hebbard P, Ivanusic J, Sha S. Ultrasound-guided supra-inguinal fascia iliaca block: a cadaveric evaluation of a novel approach. Anaesthesia. 2011 Apr;66(4):300-5.

7. Vermeylen K, Desmet M, Leunen I, Soetens F, Neyrinck A, Carens D, et al. Supra-inguinal injection for fascia iliaca compartment block results in more consistent spread towards the lumbar plexus than an infra-inguinal injection: a volunteer study. Reg Anesth Pain Med. 2019 Feb. 
8. Kumar K, Pandey RK, Bhalla AP, Kashyap L, Garg R, Darlong $\mathrm{V}$, et al. Comparison of conventional infrainguinal versus modified proximal suprainguinal approach of Fascia Iliaca Compartment Block for postoperative analgesia in Total Hip Arthroplasty. A prospective randomized study. Acta Anaesthesiol Belg. 2015;66(3):95-100.

9. Range C EC. Fascia iliaca compartment block: landmark and ultrasound approach. Anaesth Tutor Week [Internet]. 2010; 193:1-14. Available from: http://www.frca.co.uk/Documents/ 193 Fascia Iliaca compartment block.pdf.

10. Haines L, Dickman E, Ayvazyan S, Pearl M, Wu S, Rosenblum $\mathrm{D}$, et al. Ultrasound-guided fascia iliaca compartment block for hip fractures in the emergency department.J Emerg Med. 2012 Oct;43(4):692-7.

11. Evans BA, Brown A, Bulger J, Fegan G, Ford S, Guy K, et al. Paramedics' experiences of administering fascia iliaca compartment block to patients in South Wales with suspected hip fracture at the scene of injury: results of focus groups. BMJ Open. 2019 Feb;9(2):e026073.

12. Hards M, Brewer A, Bessant G, Lahiri S. Efficacy of Prehospital Analgesia with Fascia Iliaca Compartment Block for Femoral Bone Fractures: A Systematic Review. Prehosp Disaster Med. 2018 Jun;33(3):299-307.

13. Madabushi R, Rajappa GC, Thammanna PP, Iyer SS. Fascia iliaca block vs intravenous fentanyl as an analgesic technique before positioning for spinal anesthesia in patients undergoing surgery for femur fractures-a randomized trial. J ClinAnesth. 2016 Dec;35:398-403.

14. Yun MJ, Kim YH, Han MK, Kim JH, Hwang JW, Do SH. Analgesia before a spinal block for femoral neck fracture: fascia iliaca compartment block. Acta Anaesthesiol Scand. 2009 Nov;53(10):1282-7.

15. Leeper AD, Brandon PT, Morgan AVM, Cutts S, Cohen AMM. Fascia iliaca compartment block reduces morphine requirement pre-operatively for patients with fractured neck of femur. Eur J Trauma Emerg Surg. 2012 Dec;38(6):673-7.

16. Möller T, Benthaus S, Huber M, Bentrup I, SchoferM et al. A Randomized and Observer Blinded Comparison of Continuous Femoral Block and Fascia Iliaca Compartment Block in Hip Replacement Surgery. J AnestheClin Res. 2011;(4):277.

17. Garner M, Alshameeri Z, Sardesai A, Khanduja V. A Prospective Randomized Controlled Trial Comparing the Efficacy of Fascia Iliaca Compartment Block Versus Local Anesthetic Infiltration After Hip Arthroscopic Surgery. Arthroscopy. 2017 Jan;33(1):125-32.

18. Shank ES, Martyn JA, Donelan MB, Perrone A, Firth PG, Driscoll DN. Ultrasound-Guided Regional Anesthesia for Pediatric Burn Reconstructive Surgery: A Prospective Study. J Burn Care Res. 2016;37(3):e213-7.

19. Desmet M, Vermeylen K, Van Herreweghe I, Carlier L, Soetens F, Lambrecht S, et al. A Longitudinal Supra-Inguinal Fascia Iliaca Compartment Block Reduces Morphine Consumption After Total Hip Arthroplasty. Reg Anesth Pain Med. 2017;42(3):327-33.
20. Willard FH, Vleeming A, Schuenke MD, Danneels L, Schleip R. The thoracolumbar fascia: anatomy, function and clinical considerations. J Anat. 2012 Dec;221(6):507-36.

21. El-Boghdadly K, Elsharkawy H, Short A, Chin KJ. Quadratus Lumborum Block Nomenclature and Anatomical Considerations. Reg Anesth Pain Med [Internet]. 2016;41(4):548-9. Available from: https://rapm.bmj.com/content/41/4/548

22. Akerman M, Pejčić N, Veličković I. A Review of the Quadratus Lumborum Block and ERAS. Front Med. 2018;5:44.

23. Hironobu Ueshima, Hiroshi Otake and J-AL. UltrasoundGuided Quadratus Lumborum Block: An Updated Review of Anatomy and Techniques. Biomed Res Int. 2017;2017(Article ID 2752876):7 pages.

24. Blanco R, Ansari T, Riad W, Shetty N. Quadratus Lumborum Block Versus Transversus Abdominis Plane Block for Postoperative Pain After Cesarean Delivery: A Randomized Controlled Trial. Reg Anesth Pain Med. 2016;41(6):757-62.

25. Kadam VR. Ultrasound-guided quadratus lumborum block as a postoperative analgesic technique for laparotomy. Vol. 29, Journal of anaesthesiology, clinical pharmacology. 2013. p. $550-2$.

26. Ueshima $\mathrm{H}$, Hiroshi O. Intermittent bilateral anterior subcostal quadratus lumborum block for effective analgesia in lower abdominal surgery. Vol. 43, Journal of clinical anesthesia. United States; 2017. p. 65.

27. Maenchen N, Hansen C, Dam M, Børglum J. International Journal of Anesthetics and Anesthesiology Case Report: Open Access Ultrasound-guided Transmuscular Quadratus Lumborum (TQL) Block for Pain Management after Caesarean Section. Vol. 2016, International Journal of Anesthetics and Anesthesiology. 2016.

28. Carline L, McLeod GA, Lamb C. A cadaver study comparing spread of dye and nerve involvement after three different quadratus lumborum blocks. Br J Anaesth. 2016 Sep;117(3): 387-94.

29. Elsharkawy H. Quadratus lumborum block with paramedian sagittal oblique (subcostal) approach. Vol. 71, Anaesthesia. England; 2016. p. 241-2.

30. Stuart Green M, Ryan Hoffman C, Iqbal U, Olabisi Ives O, Hurd B. Transmuscular Quadratus Lumborum Block Reduces Length of Stay in Patients Receiving Total Hip Arthroplasty. Anesthesiol pain Med. 2018 Dec;8(6):e80233.

31. Seidel R, Barbakow E. [Surgical treatment of proximal femoral fractures in high-risk geriatric patients under peripheral regional anesthesia: A clinical case series]. Anaesthesist. 2019 Feb;68(2):108-14.

32. Tulgar S, Ermis MN, Ozer Z. Combination of lumbar erector spinae plane block and transmuscular quadratus lumborum block for surgical anaesthesia in hemiarthroplasty for femoral neck fracture. Indian J Anaesth. 2018 Oct;62(10):802-5.

33. Tulgar S, Kose HC, Selvi O, Senturk O, Thomas DT, Ermis $\mathrm{MN}$, et al. Comparison of Ultrasound-Guided Lumbar Erector Spinae Plane Block and Transmuscular Quadratus Lumborum Block for Postoperative Analgesia in Hip and Proximal 
Femur Surgery: A Prospective Randomized Feasibility Study. Anesth essays Res. 2018;12(4):825-31.

34. McCrum CL, Ben-David B, Shin JJ, Wright VJ. Quadratus lumborum block provides improved immediate postoperative analgesia and decreased opioid use compared with a multimodal pain regimen following hip arthroscopy. J hip Preserv Surg. 2018 Aug;5(3):233-9.

35. Adhikary SD, Short AJ, El-Boghdadly K, Abdelmalak MJ, Chin KJ. Transmuscular quadratus lumborum versus lumbar plexus block for total hip arthroplasty: A retrospective propensity score matched cohort study. J AnaesthesiolClinPharmacol. 2018;34(3):372-8.

36. La Colla L, Ben-David B, Merman R. Quadratus Lumborum Block as an Alternative to Lumbar Plexus Block for Hip Surgery: A Report of 2 Cases. A A case reports. 2017 Jan;8(1):4-6.

37. Johnston DF, Sondekoppam RV. Continuous quadratus lumborum block analgesia for total hip arthroplasty revision. Vol. 35, Journal of clinical anesthesia. United States; 2016. p. 235-7.
38. Ahiskalioglu A, Yayik AM, Alici HA, Ezirmik N. Ultrasound guided transmuscular quadratus lumborum block for congenital hip dislocation surgery: Report of two pediatric cases. J ClinAnesth [Internet]. 2018;49:15-6. Available from: http://www. sciencedirect.com/science/article/pii/S0952818018306263

39. Ince I, Hamadnalla H, Hassan M, Qiu Y. Ultrasound-guided quadratus lumborum plane block for congenital hip dislocation surgery: Dermatomes and osteotomes. J ClinAnesth [Internet]. 2019;54:140. Available from: http:/www.sciencedirect.com/ science/article/pii/S0952818018312625

40. Wikner M. Unexpected motor weakness following quadratus lumborum block for gynaecological laparoscopy. Vol. 72, Anaesthesia. England; 2017. p. 230-2.

41. Bugada D, Bellini V, Lorini LF, Mariano ER. Update on Selective Regional Analgesia for Hip Surgery Patients. AnesthesiolClin [Internet]. 2018 Sep 1;36(3):403-15. Available from: https://doi.org/10.1016/j.anclin.2018.04.001

\section{Sažetak \\ PRIMJENE I KRITIČKA EVALUACIJA BLOKA ODJELJKA FASCIJE ILIACE I QUADRATUS LUMBORUM BLOKA U ORTOPEDSKIM ZAHVATIMA}

\section{Plečko, I. Bohaček, B. Tripković, M. Čimić, M. Jelić i D. Delimar}

Prednji dio čahure zgloba kuka nerviraju n. femoralis i n. obturatorius, dok stražnji dio čahure inervira n. musculi quadratus femoris i povremeno n. glutealis superior (posterolateralni dio) i n. ischiadicus (posterosuperiorni dio). Jedna od mogućnosti za primjenu regionalne anestezije u kirurgiji zgloba kuka je blok odjeljka fascije iliace (FICB), koji zahvaća živce bitne za inervaciju kuka te senzornu inervaciju bedra - n. femoralis, n.obturatorius i n. cutaneus femoris lateralis. FICB se može izvesti relativno jednostavno i predstavlja dobru opciju za zbrinjavanje fraktura kuka u hitnim situacijama. Dokazano je kako smanjuje upotrebu morfija preoperativno u pacijenata s frakturom vrata femura, a može biti indicirani za artroplastiku kuka, artroskopije kuka te sanaciju opeklina u regiji bedra. Quadratus Lumborum blok (QLB) spada u blokove stražnjeg abdominalnog zida te se provodi isključivo pod kontrolom ultrazvuka. Još uvijek nije razjašnjen točan mehanizam njegovog djelovanja. Dokazano je kako prednji QLB dovodi do smanjenja trajanja boravka u bolnici i smanjenja upotrebe opioida nakon operacija kuka. Također, pokazao se kao uspješnija metoda perioperativne analgezije u bolesnika u kojih se provodi zahvat na kuku ili proksimalnom femuru u usporedbi sa standardnom intravenskom analgezijom, te omogućuje ranu mobilizaciju pacijenata, što smanjuje pojavnost duboke venske tromboze i tromboembolijskih komplikacija. S druge strane, neki živčani ogranci koji sudjeluju u inervaciji zgloba kuka nisu zahvaćeni s QLB, što također treba uzeti u obzir. QLB se pokazao kao potencijalna opcija za anesteziju u kirurgiji kuka, no tek se treba dokazati njegova pouzdanost.

Ključne riječi: inervacija kuka; regionalna anestezija; ortopedija; blok odjeljka fascije iliace; quadratus lumborum blok 